Maria Luiza Gava Schmidt

Pedro Henrique Godinho'

Departamento de Psicologia Experimental e do Trabalho da Faculdade de Ciências e Letras da Universidade Estadual Paulista, Assis - SP, Brasil.

\section{Um breve estudo acerca do cotidiano do trabalho de produtores rurais: intoxicações por agrotóxicos e subnotificação}

\section{A brief study on the rural producers' daily routines: poisoning by pesticides and un- der-reporting}

\begin{abstract}
Resumo
Pesquisas na área da Saúde no Trabalho têm revelado a preocupação com os agravos à saúde de trabalhadores rurais decorrentes da utilização de defensivos agrícolas. Diante disso, este estudo objetivou conhecer o cotidiano de trabalho de produtores rurais de uma cooperativa agrícola localizada no interior do estado de São Paulo, bem como avaliar a exposição deles quando da utilização de agrotóxicos no desenvolvimento de suas atividades. Esperamos, com base nos resultados, estar contribuindo com discussões sobre o tema relacionado à saúde dos trabalhadores no contexto considerado. Para coleta de dados, utilizamos entrevistas semi-estruturadas, aplicadas de formas individual e coletiva. Participaram do estudo cinqüenta produtores rurais que desenvolvem atividades nas lavouras de café, soja, trigo e milho. Os dados foram agrupados em cinco categorias e analisados qualitativamente. Os resultados expõem as características da atividade agrícola na região, a utilização dos equipamentos de proteção individual, as técnicas no uso dos agrotóxicos, o sofrimento psíquico e a produção rural e maneiras de lidar com as situações de intoxicação e alertar os órgãos competentes para o problema da subnotificação.
\end{abstract}

Palavras-chaves: saúde do trabalhador, intoxicação por agrotóxicos, subnotificação de agravos à saúde.

\begin{abstract}
The harmful effects of pesticides on the rural workers' health have been causing concern within the Occupational Health area. Due to this fact, our research aims not only at getting acquainted with the rural producers' daily routine in an agricultural co-operative society located in the countryside of São Paulo, but also at evaluating the amount of pesticide they are exposed to while carrying out their tasks. We hope the results will offer a contribution to the discussions on this issue. The data was collected through semi-structured interviews conducted either individually, or in groups. Fifty coffee, soy, wheat and corn producers were researched. The resulting datum were classified in five categories and analyzed qualitatively. They show the features of the rural activities in the area, the use of Personal Protective Equipment, the different techniques in applying pesticides, psychological damages, rural production, ways of dealing with poisoning and warning the involved governmental and non-governmental organizations about under-reporting.
\end{abstract}

Keywords: workers' health, poisoning by pesticides, under-reporting on heath damages. 


\section{Introdução}

Nas últimas décadas, o processo produtivo do meio rural tem enfrentado modificações profundas que visam a atender à competitividade do agronegócio. Tais mudanças no processo produtivo envolvem, sobretudo, a mecanização das lavouras e a implementação de técnicas associadas ao aumento da utilização de agentes químicos, ou seja, os defensivos utilizados no controle de pragas, conhecidos, na literatura, como agrotóxicos.

Publicações referentes ao tema relacionado ao trabalho rural (FARIA et al., 2004; MOREIRA et al., 2002; PERES et al., 2004; ROZEMBERG et al., 2004; entre outros) mostram que essas mudanças contribuem para aumentar a exposição dos trabalhadores do meio rural a riscos de acidentes e doenças relacionados ao trabalho, principalmente quando o assunto refere-se ao uso de agrotóxicos.

Os casos de óbito por intoxicação conseqüente desses defensivos são registrados em bancos de dados de controle de toxicologia, tais como Sinitox (Sistema Nacional de Informação Tóxico-Farmacológica), Sinan (Sistema de Informações de Agravos de Notificação) e Sindag (Sindicato Nacional da Indústria de Produtos para Defesa Agrícola), entre outros. Os índices registrados são preocupantes como se pode depreender da literatura específica. No entanto, é conhecido o fato da subnotificação dessas ocorrências pelas instituições de saúde.

Nossa área de atuação está centrada em estudos no campo da Saúde Coletiva, especificamente no que tange à Saúde do Trabalhador. Nossos projetos de pesquisa

\section{Metodologia}

O local escolhido para coleta de dados foi uma cooperativa agrícola localizada no interior do estado de São Paulo. Fundada no final da década de 1950, teve a sua origem na cultura do café, sendo esta a principal atividade agrícola da região até o início da década de 1970. A partir de então, a cultura do café foi sendo substituída pelas culturas de soja, trigo e milho, intensificando a mecanização e a utilização de tecnologias que visavam ao aumento da produtividade, dentre elas o uso de defensivos agrícolas. estão vinculados ao Núcleo de Saúde do Trabalhador do Departamento de Psicologia Experimental e do Trabalho da Unesp (Universidade Estadual Paulista) - Campus de Assis. Este Núcleo visa a desenvolver pesquisas em organizações e/ou instituições com o objetivo de identificar aspectos do trabalho que possam estar produzindo efeitos desfavoráveis à saúde dos trabalhadores e, diante dos resultados obtidos, sugerir estratégias que promovam a melhoria da qualidade de vida da população trabalhadora.

Assim sendo, o projeto proposto, além de atender aos objetivos deste Núcleo, justifica-se pelo fato de não termos encontrado, na literatura, estudos que retratem a saúde dos produtores rurais na região a que nos propusemos estudar. Além disso, os registros de casos de intoxicação por agrotóxicos notificados junto à Diretoria Regional de Saúde, cuja área de abrangência corresponde à região do estudo, apresentaram um índice de registro questionável, uma vez que, no período de 1998 a 2003, houve apenas três casos notificados. (SINAN, 2004). Tal fato, a nosso ver, apresenta-se incoerente com a realidade, pois a região de abrangência é uma área reconhecida em termos de agropecuária e agricultura, na qual há uso intensivo de agrotóxicos.

Diante disso, os objetivos que nortearam este estudo foram:

- Conhecer o cotidiano de trabalho dos produtores rurais dessa região;

- Avaliar a exposição desses trabalhadores quando da utilização de agrotóxicos no desenvolvimento de suas atividades.

Atualmente, a cooperativa possui aproximadamente 1.800 cooperados.

Para coleta de dados, utilizamos como instrumento a entrevista semi-estruturada. O roteiro da mesma foi composto por perguntas abertas e fechadas e contemplou questões relacionadas à descrição do processo de trabalho, a queixas referentes à saúde, técnicas utilizadas no cotidiano de trabalho, sobretudo quando do uso de agrotóxicos, cuidados gerais com a saúde, dificuldades encontradas no dia-a-dia de trabalho. Durante a realização das entre- 
vistas, foram surgindo novas questões por meio das quais esclarecemos nossas dúvidas e aprofundamos nosso conhecimento sobre o fato.

As entrevistas foram realizadas de forma individual e coletiva, sendo 11 individuais. As coletivas foram aplicadas da seguinte forma: um grupo com 4 participantes, um grupo com 6 participantes e, por último, um grupo composto de 29 participantes.

A duração da aplicação individual oscilou entre meia hora e 1 hora e meia. A aplicação grupal durou aproximadamente duas horas. As entrevistas foram aplicadas em diferentes locais, sendo que a maioria delas foi realizada nas salas localizadas nas dependências da cooperativa. Três foram realizadas nas residências dos agricultores e uma, na lavoura, durante a colheita de trigo.

O contato com os participantes, feito aleatoriamente, foi facilitado pelos agrônomos e funcionários alocados nos balcões das lojas nas unidades da cooperativa.

\section{Resultados e Discussão}

Contribuíram para o estudo preliminar 50 produtores rurais. Destes, 49 entrevistados pertenciam ao sexo masculino e apenas um ao sexo feminino. A idade predominante dos participantes situa-se na faixa etária entre 33 e 63 anos.

Do total de 50 entrevistados, 34 eram pequenos produtores (área máxima equivalente a 50 hectares) e os demais, médios e grandes (área acima de 50 hectares), conforme classificação da cooperativa.

Constatou-se um baixo nível de escolaridade, sendo que mais da metade dos entrevistados tem o Ensino Fundamental incompleto. Esse dado pode estar associado ao fato da maioria ter relatado, durante a entrevista, que trabalha na lavoura desde a infância, ficando, deste modo, impossibilitada da continuidade de estudos.

Para análise dos dados, inicialmente fizemos um levantamento de temas que sobressaíram nas falas dos entrevistados. Posteriormente, os temas foram agrupados em cinco categorias de análise descritas abaixo e que se encontram respaldados na bibliografia pertinente.
A participação dos entrevistados ocorreu de forma voluntária e os resultados foram tratados confidencialmente.

Em nosso contato com a cooperativa, foi possível observarmos, ainda, aspectos mais gerais relacionados à organização do trabalho dos entrevistados, especificamente em relação ao fluxo de trabalhadores durante os processos de plantio, tratamento fitossanitário e colheita, momentos em que a aplicação das entrevistas foi suspensa devido à indisponibilidade de tempo dos mesmos.

O tratamento dos dados foi feito qualitativamente, tomando-se como referência as concepções metodológicas de Minayo (1999).

De acordo com essa autora:

a pesquisa qualitativa trabalha com o universo de significados, motivos, aspirações, crenças, valores e atitudes, o que corresponde a um espaço mais profundo das relações, dos processos e dos fenômenos que não podem ser reduzidos à operacionalização de variáveis. (MINAYO, 1999, p. 21-22)

Dada a natureza do trabalho que pretendemos apresentar, adotamos uma amostragem qualitativa. De acordo com Minayo (2002, p. 43): "A pesquisa qualitativa não se baseia em critério numérico para garantir sua representatividade".

Nesse sentido, quando direcionamos nossos objetivos para compreender o cotidiano desses trabalhadores, estamos apreedendo dados dos habitus desses atores sociais, seus valores, suas idéias e modos de comportamento que obedecem a um modelo cultural interiorizado, vivenciados em comum pelo grupo.

Característica da atividade agrícola na região e a exposição ocupacional aos agrotóxicos

A área de atuação da cooperativa estende-se por todo o Médio Vale do Paranapanema, o que compreende aproximadamente 160 mil hectares de produção de grãos, sendo as principais culturas a soja, o milho, o trigo, além da cana-de-açúcar, da mandioca e do café.

As medidas de controle de pragas acontecem por meio da aplicação intensiva de agrotóxicos. Os grupos químicos mais uti- 
lizados pelos entrevistados são organofosforados, glifosato, piretróides e 2,4-D.

As medidas de controle de pragas por meio de métodos não-químicos parecem estar longe de serem implementadas na região, sobretudo devido à falta de conhecimento dos entrevistados acerca de tais métodos.

Dos 50 participantes, apenas três relataram conhecer métodos naturais para o controle de pragas. Contudo, percebemos, pelos discursos dos mesmos, que há descrença em relação a esse sistema de controle: "O meu vizinho usou e não surtiu efeito" (médio agricultor, 33 anos).

É possível percebermos também a descrença em relação à eficácia do próprio agrotóxico:

Não tem produto que resolve as pragas, às vezes nem veneno dá jeito. (médio agricultor, 38 anos)

$\mathrm{O}$ veneno mata a gente e não mata a lagarta, no ano passado teve um ataque de lagarta que nenhum veneno matava, pergunta pros técnico como foi difícil terminar com elas. (pequeno agricultor, 43 anos)

Durante a aplicação da entrevista em grupo, um dos entrevistados fez o seguinte comentário: "Método sem ser o veneno, só benzimento e cortar a lagarta com gilete".

Avaliando os indicadores de tamanho de área, observamos que os pequenos produtores apresentam maior exposição química nas diferentes formas de exposição. Já os médios e grandes produtores, devido à maior renda financeira, optam pela adaptação das máquinas e equipamentos agrícolas como, por exemplo, adaptar cabines a tratores e colheitadeiras (para melhorar o conforto e a segurança nas aplicações e nos serviços nas lavouras) ou então delegam as atividades laborativas aos empregados, ficando, estes últimos, expostos a riscos.

Técnica e as "técnicas" no uso de agrotóxicos

São bem conhecidas as atitudes dos trabalhadores do meio rural com relação à exposição a riscos ocupacionais por intoxicação, tais como aplicação dos produtos contra o vento, mistura de agrotóxicos, desentupimento de bicos de bomba de produtos com a boca, uso de ferramentas utilizadas para abrir frascos de produtos para outros fins, falta de higiene pessoal como, por exemplo, a adequada lavagem das mãos após o manuseio e/ou aplicação dos produtos e o uso de equipamentos contaminados com agrotóxicos por mais de uma vez, dentre outros.

Durante uma das entrevistas, fomos acompanhados pelo agrônomo responsável pela área e, ao final, perguntamos se havia alguma questão a ser feita ao entrevistado. Este sugeriu que perguntássemos sobre como era feito o desentupimento os bicos dos pulverizadores, uma vez que o agrônomo já teria presenciado o agricultor desentupindo bicos de pulverizadores com a boca durante uma visita ao sítio. Acatamos a sugestão formulando, a seguir, a pergunta. Eis a resposta: "Os bicos têm que assoprar, se cutucar com arame ou chave, estraga os bico" (médio agricultor).

Numa outra entrevista, realizada na residência do entrevistado, observamos que o mesmo fazia uso de um canivete no cinturão. Fizemos a seguinte pergunta: "O que você usa para abrir os frascos dos produtos?" Nesse instante, o entrevistado apontou para o canivete e comentou: "Com um canivete, esse aqui, ó”. Continuamos a entrevista: "Além de usar esse canivete para abrir os frascos dos produtos, você utiliza o mesmo para outras coisas?", e o entrevistado respondeu que sim:

Ah! Sim, pra tudo, cascar laranja, pra tudo que precisar, apareceu uma fruta a gente come. É só passar uma aguinha e tá pronto pra uso. (grande agricultor, 39 anos)

Outro ponto observado na análise das entrevistas refere-se à falta de treinamento técnico quando da utilização dos agrotóxicos.

Dentre os entrevistados, apenas um respondeu que não procura técnico especializado quando necessita de algum produto. Todos os demais buscam orientação de agrônomo e/ou técnico especializado.

Entretanto, as falhas técnicas de dosagem aparecem em comentários feitos por alguns entrevistados:

As pessoas usam dosagem errada de produtos, às vezes mais, às vezes menos Usam mais para matar a praga mais rápido e menos para economizar. Há falta de confiança naquele que receita o produto, acham que os agrônomos levam vantagem ao receitar os produtos. (pequeno agricultor, 56 anos)

Antigamente a gente fazia as mistura por rumo, agora o agrônomo tá orientando e a gente tá fazendo na risca. (médio agricultor, 38 anos) 
A gente tinha um cunhado que era meio agrônomo, a gente fazia com as orientações dele, agora a gente segue as orientações, já fiz coisa pela minha conta e deu errado. (grande agricultor, 39 anos)

Na hora quente do dia eu não passo, espero refrescar um pouco senão evapora muito veneno... Quando tá ventando eu não passo, pois voa na gente e desperdiça muito. (médio agricultor, 53 anos)

A maioria dos entrevistados começou a trabalhar muito cedo na lavoura, desde a infância, e, dessa forma, o aprendizado foi ocorrendo no dia-a-dia por meio do contato com os mais velhos: "A gente vai aprendendo sozinho, vai vendo e vai aprendendo" (pequeno agricultor, 56 anos).

$\mathrm{O}$ descaso em relação às situações de risco aparece relacionado também ao transporte de produtos químicos do local da compra até a residência e ainda do local onde se encontra armazenado até a lavoura, e vice-versa.

Quando perguntamos sobre as formas de transporte dos produtos, percebemos que, embora a maioria dos entrevistados tome os cuidados necessários durante o transporte de tais produtos, alguns discursos denunciam o descaso: "Vem junto com farelo de porco, a gente vai na cidade faz compra e vem tudo junto" (grande agricultor, 39 anos).

No caso do transporte, o cuidado aparece cooperado ao cumprimento da legislação de trânsito: "Na pista não pode carregar veneno, se a polícia pega dá problema”.

Durante seus discursos, os participantes manifestaram a falta de orientação técnica por parte dos agrônomos no que tange aos cuidados com a saúde: "Os agrônomos deveriam orientar, eles deveriam passar e mostrar os riscos" (pequeno agricultor, 56 anos).

A falta de cuidado técnico é preocupante, sobretudo em relação ao descarte de embalagens. Apesar da cooperativa disponibilizar postos próprios e conveniados apropriados para o recebimento das embalagens tríplice-lavadas e a grande maioria dos entrevistados apontar que faz corretamente a devolução, há alguns discursos que denunciam o descaso em relação ao procedimento, o que denota a falta de conscientização de alguns sobre o problema relacionado à contaminação ambiental em decorrência do descarte inapropriado. Eis alguns relatos emitidos por participantes durante a aplicação de entrevistas grupais:
"Se falarem que não reutilizam as embalagens estão mentindo, todo mundo reutiliza"; "Tem produtor que queima as embalagens"; "Tem produtor que sai jogando as embalagens no sítio dos outros"; "Tem pessoas que não são produtores que usam as embalagens de veneno para armazenar outras coisas... pegam nos sítios".

Quando questionado sobre tais cuidados, um dos entrevistados relatou que o vizinho queimou os litros vazios de veneno, saindo uma fumaça preta. Afirmou ter explicado que aquilo estava errado, mas de nada adiantou: "Antes eu queimava, mas agora eu parei" (agricultor, 54 anos). "Não queimo, não enterro e não devolvo, deixo amontoado ao ar livre..." (pequeno agricultor, 41 anos)

Há também o problema relacionado à falta de espaço para a devida armazenagem das embalagens vazias:

Não tão recebendo as embalagens, eu resolvi o problema, juntei tudo e taquei fogo.

A gente tá guardando as embalagens em casa, pois não tem nenhum lugar recebendo... Outro dia as crianças pegaram os galões de veneno pra brincar. (médio agricultor, 38 anos)

Tenho um monte de embalagens e não sei o que fazer com elas. (médio agricultor, 53 anos)

Ao adentrarmos um sítio para realizarmos uma entrevista, observamos que havia uma embalagem vazia encostada no mourão da porteira.

Quando questionado sobre o descarte das embalagens, durante a entrevista, nosso entrevistado imediatamente olhou em direção à porteira: "Olha tem um galão meu aí (rs). Faz um mês que está aí, vou tirar daí hoje”. Na seqüência, queixou-se dos problemas que estava encontrando para devolver as embalagens. "Guardo numa casa velha, mas já ta lotada. Tinha que ter um lugar certo pra estocar, dá vontade de tocar fogo, não pode enterrar, não pode entregar, vai fazer o quê?"

J., 33 anos, formado em Administração de Empresas, bastante preocupado com os problemas relacionados ao uso de agrotóxicos, acrescentou o seguinte comentário: 
Deveria ter palestras sobre os cuidados com agrotóxicos aqui na Cooperativa, com a participação dos empregados, deveria ter nestas palestras orientação sobre as embalagens, uso de máscara, roupas... $\mathrm{O}$ patrão tem que ficar controlando pra eles (se referindo aos empregados) usarem proteção. Às vezes eles saem pra aplicar veneno de madrugada, eu não sei se estão se protegendo.

Esse mesmo entrevistado destacou a necessidade de palestras sobre Primeiros Socorros. Contou que, certa vez, um parente estava transportando o empregado em cima da caminhonete e, por algum motivo, ele se feriu. No ferimento do empregado colocou-se óleo diesel, o que trouxe inúmeras conseqüências.

Outro entrevistado, ao relatar sobre essas questões, afirmou que gostaria de receber orientação de técnicos especializados sobre cuidados com a saúde. Segundo ele:

Tem pessoas que abusam da utilização do veneno, não usam equipamentos de proteção, fumam durante a aplicação do veneno e passam produtos em dia de vento. (pequeno agricultor, 41 anos)

Com base nas falas dos entrevistados, percebemos que o coletivo desses trabalhadores cria o perfil característico daquele que é conhecido como o bom "Passadô de Veneno".

Ouvimos esse termo pela primeira vez durante uma das entrevistas: "Seria importante entrevistar o meu irmão porque ele é o "passadô de veneno"” (pequeno agricultor, 42 anos).

Acatamos a sugestão e entramos em contato com o irmão. Eis o discurso do "Passadô de Veneno":

Eu sô o 'passadô de veneno' aqui, em caso eu me cuido, a gente vê o pessoal aí passando veneno sem usá máscara, sem nada até sem chapéu, com o rádio ligado passando veneno sem equipamentos. Os outros (se referindo aos irmãos) não querem passá mais, tem que tê prática, os outros passam maceta (no sentido de amassar), eu passo pra eles, meu irmão vai fazê maceta, eu não gosto, eu gosto de eu mesmo fazê. Ele não sabe passar e pede 'vai lá passá pra mim'. Às vezes, passando veneno, você faz uma confusão, muito em cima perde veneno, muito embaixo não mata, eu tô acostumado passá, toda vida eu passo veneno. (grande agricultor, 39 anos)

Outro entrevistado que deixou de passar o veneno há cinco anos delegou essa atividade para o filho mais novo e salientou:

Deixei essa tarefa pra ele porque o filho mais velho é cabeçudo, não sabe calcular direito os espaços para distribuir a quantidade certa de veneno. Ele tem mais percepção, toma mais cuidado. (pequeno agricultor, 56 anos)

Outro aspecto considerado interessante foi que, em algumas famílias, o "Passadô de Veneno" vai sendo substituído gradualmente de acordo com a idade, passando, de início, do pai ao primogênito e assim sucessivamente, de acordo com a idade cronológica dos irmãos, como numa passagem de bastão.

Em outras situações, a substituição do "Passadô de Veneno", na esfera familiar, acontece logo após uma ocorrência de intoxicação. No caso, se o pai ou o irmão mais velho sofre intoxicação, é substituído pelo mais novo. Quando não há membros suficientes no contexto familiar, opta-se pela contratação de alguém para executar a atividade de manuseio dos agrotóxicos.

Entretanto, salientamos que tais aspectos não podem ser generalizados, pois não colhemos dados específicos sobre esse assunto. Esclarecemos aqui, apenas a título das observações colhidas, que entendemos ser de extrema importância tal investigação.

Os dados acima apresentados nos dão uma noção de como a organização do trabalho no meio rural, especificamente no que tange à utilização de agrotóxicos, está estruturada para ser executada.

Segundo Paraguay (2003, p. 812), “todo trabalho tem e revela uma organização, pois mostra as idéias que norteiam o porquê e como deveria ser feito". No entanto, a autora afirma que:

em todo trabalho humano há uma parte
prevista, proposta, oficial, projetada para
aquele trabalho, e outra parte ou versão
mais concreta, do como ele é feito na
prática - no cotidiano - que nem sempre
coincide com a primeira.

Diante dessas concepções, a autora salienta que o conhecimento das reais condições de execução das atividades laborativas é fundamental para melhorar aspectos da relação com a saúde nos ambientes de trabalho.

Eu tenho um vizinho que planta tomate. Um dia passei na lavoura dele e vi uma área de plantação de tomate feínho. En- 
tão, perguntei pra ele por que aquela área estava separada. Ele respondeu: "Aqueles eu planto pra comer, porque esses aqui eu não como, porque nesses eu passo muito veneno. Eu só como aqueles".

Enfim, por meio de seus discursos, os entrevistados vão revelando seus "macetes”, conforme denominado por Dejours (1992, p. 105), ou seja, "um saber que não está escrito, não se formaliza, mas simplesmente circula entre os trabalhadores", sendo os mesmos partilhados coletivamente.

Esses macetes, por sua vez, caracterizam a descrença nos técnicos de nível universitário, no caso, os agrônomos: não há credibilidade no conhecimento teórico de que estes profissionais dispõem e, sendo assim, são percebidos de forma insignificante frente ao conhecimento prático dos agricultores, pois nem sempre estes adotam as prescrições emitidas e cada um age como pode.

Os equipamentos de proteção individual: justificativas para não os usar

Soma-se às atitudes ocupacionais de exposição ao risco, a recusa a certas normas de segurança, sobretudo ao uso de Equipamentos de Proteção Individual (EPI).

A recusa às regras de segurança aparece de forma expressiva no que tange ao não uso dos equipamentos indicados para proteção contra intoxicação, como calças compridas de brim grosso e de cor clara, camisa de brim ou algodão, ou macacão de brim grosso, com mangas compridas e de cor clara, luvas e botas impermeáveis, proteção impermeável para a cabeça, protetores faciais e óculos de segurança, respiradores com filtros adequados e botas de borracha.

As justificativas para o não uso desses equipamentos foram manifestadas pelos entrevistados em três situações distintas, a saber: desprezo pelos equipamentos devido à incerteza quanto à eficácia dos mesmos, queixas de incômodos e atropelos das atividades do dia-a-dia.

As atitudes de desprezo pelo uso de EPIs centram-se nas atividades de preparo e aplicação dos produtos, situações em que o uso desses equipamentos, ainda que seja mínimo, é considerado fundamental para a proteção.

Os agricultores que não utilizam EPI o fazem por não reconhecerem a eficácia dos equipamentos:
Nos tornamos resistente ao veneno como o bicho da soja. (agricultor, 54 anos)

Quando o produto é forte, classe I, a gente usa, quando o produto é fraco, a gente dá uma relaxada e não usa EPI... Quando estou passando produto que não tem cheiro, não uso EPI. (grande agricultor, 41 anos)

Tem dia que eu não uso nada pra passar agrotóxico, uso aquelas máscaras vagabundas que não adianta nada. (pequeno agricultor, 52 anos)

Com relação ao uso de luvas, este mesmo agricultor comentou: "Você suja a luva, tira uma, depois quando vou tirar a outra sujo a mão". Nesse relato, percebemos que a descrença em relação à eficácia dos EPIs pode estar relacionada à falta de técnica para utilizá-los. Nesse caso específico, a luva contaminada com agrotóxico deveria ter sido lavada antes de ser retirada, o que não ocorreu.

Durante as entrevistas, foram muitas as queixas relacionadas ao desconforto causado pelo uso de EPIs, exemplificadas com os relatos subseqüentes:

O equipamento incomoda, você tem que mexer na bomba, tem que ser rápido, é muito veneno que a gente tem que aplicar. (pequeno agricultor, 38 anos)

Os cuidados que a gente tem com veneno é muito pouco. Às vezes a gente passa dessecante na terra aí a gente vai incorporar e aquela poeira faz mal. Os equipamentos deixa desesperado, atrapalha. (grande agricultor, 39 anos)

As vestimentas são quentes, incomodam, a máscara sufoca. (pequeno agricultor, 41 anos)

Os caras que inventaram aquele roupão pra passar veneno deviam usar no calor, ninguém consegue usar um negócio daqueles. (pequeno agricultor, 52 anos)

Tem que ter paciência pra usar aquilo, com o sol quente fica difícil agüentar. Agora é o meu irmão quem passa veneno, ele usa equipamento senão vai todo mundo morrer junto, é uma herança. (médio agricultor, 38 anos)

Não gosto de pôr muito não, me sinto mal, o bafo do veneno penetra e abafa, é pior. (pequeno agricultor, 63 anos)

Durante a aplicação das entrevistas ao grupo, os participantes fizeram também comentários acerca dos EPIs, tais como: "A luva que fazem pra usar o veneno não presta, usar ou não a contaminação é do mesmo jeito"; "O equipamento é muito ruim”; "O problema do EPI é que é muito desconfortável”; "O EPI incomoda, a máscara sufo- 
ca a respiração"; "O equipamento é muito desconfortável, a máscara queima a cara da gente"; entre outros.

De primeiro eu passava veneno de bermuda, agora uso calça jeans... Aquelas luvas não agüentam nada, rasga, então, largo mão. Aquele roupão é muito quente, dá falta de ar, não acostumo. Comprei um macacão porque todo mundo tinha comprado, mas não dá pra usar, é muito quente. (médio agricultor, 53 anos)

No entanto, essa atitude de descrédito não pode ser entendida como ignorância e/ ou inconsciência em relação ao risco. Esta aparece na forma como descreveu Dejours (1992), como uma fachada, ou seja, como uma forma de neutralizar o medo de exposição aos produtos.

Para o referido autor, a negação e o descrédito pelo perigo resultam da percepção dos trabalhadores de que as medidas de segurança não são suficientes para evitar todos os riscos de danos à saúde a que eles estão expostos. Por isso, preferem não se lembrar daquilo que penosamente tentam se livrar resistindo às campanhas de segurança.

Tomando como referência as concepções desse autor, quando analisamos os discursos dos entrevistados, entendemos que a recusa e as resistências às regras de segurança visam a "suportar justamente o risco que não seria completamente atenuado por medidas de segurança ridículas em relação à importância do risco" (DEJOURS, 1992, p. 71).

Além disso, em algumas situações do cotidiano, a ansiedade relativa às perdas da produção faz com que os trabalhadores se apressem e deixem de cumprir regras básicas de proteção. Sendo assim, esse atropelo do dia-a-dia expõe inevitavelmente os trabalhadores ainda mais a situações de risco.

Muitos cooperados não têm trator com proteção para passar veneno e, quando a praga ataca a lavoura, o desespero para eliminá-la faz com que estes se expõem aos riscos como, por exemplo, passar veneno em dia de vento, jogando o veneno sobre o próprio corpo... (médio agricultor, 56 anos)

Depende da necessidade, depende do tempo. Tem hora que a gente é obrigado, não tem como, o agrônomo orienta que não pode passar, a praga tá comendo, tá estragando, daí tem que passar. A gente evita o máximo, mas não tem como... Tem hora que tem que entrar no meio do vento e passar, precisam passar, não tem como, o pior do veneno é o vento, o vento é terrível, se põe os óculos ele acha um lugar de entrar. (grande agricultor, 39 anos)

Há aqueles que, embora reconheçam a necessidade e a importância do uso, não o fazem porque os equipamentos apresentam muitos incômodos. Isso pode ser percebido no seguinte relato: "A maioria das pessoas não usa equipamento porque incomoda, é quente, soa” (pequeno agricultor, 54 anos).

Soma-se a estas questões o fator econômico. Um dos entrevistados, comentando sobre os EPIs, relatou: “O macacão só pode dar trinta lavada, não lavo em cada aplicação, uso várias vezes sem lavar porque o macacão é caro" (agricultor, 39 anos). A mãe do mesmo relata: "Deixo numa sacolinha pendurado no quartinho".

Cadê o dinheiro pra pôr cabine, cadê o incentivo do governo, não tenho cabine no trator porque é muito caro. A gente planta milho e põe a fé em Deus. Isso aqui (se referindo à entrevista) não vai prejudicar os empréstimos, vai? (pequeno agricultor, 43 anos)

Agricultor não usa equipamento porque é pão duro, uma máscara boa custa noventa reais. Eles não se protegem, já vi gente mexendo veneno com as mãos. (médio agricultor, 33 anos)

Percebemos, também, nos discursos dos entrevistados, que estes criam maneiras próprias de proteção, tais como adequação de uma determinada técnica, criação de um tipo de proteção individual como, por exemplo, em "dia de vento viro a bomba pro lado".

Entrevistamos uma agricultora de 62 anos que, durante a entrevista, relatou trabalhar na lavoura desde a infância. Segundo ela, nunca fez uso de equipamento de proteção, trabalha calçada com chinelo e protege os pés colocando uma sacola plástica.

Já outro entrevistado, de 42 anos, afirmou que toma cuidado apenas quando o veneno tem cheiro forte. Nesse caso, para se proteger, amarra um pano no rosto, procura evitar aplicar o produto nos horários em que há vento, lavando bem as mãos após o manuseio.

Perguntamos aos nossos entrevistados como sabem se o veneno é perigoso. Dentre as respostas dos 50 entrevistados, apenas um relatou que reconhece porque lê as bulas, sendo que o mesmo possui Ensino Médio completo. Os demais responderam 
que reconhecem se o veneno é perigoso pela cor do rótulo, pelo desenho da caveira na faixa da embalagem e, sobretudo, pelo cheiro: "Não tem veneno que não é perigoso, uns é mais perigoso que os outros, mas são todos perigosos”.

\section{Sofrimento psíquico na produção rural}

Analisando os discursos dos entrevistados, encontramos dois componentes de ansiedade que contribuem para caracterizar o sofrimento psíquico dos trabalhadores, na forma como descreveu Dejours (1992).

Temos o sofrimento proveniente da ansiedade relativa à degradação do organismo, conceituada pelo autor como sendo aquela que paira sobre a saúde física.

No caso dos agricultores, as más condições de trabalho colocam o corpo em perigo, tanto em relação ao trabalho penoso, à exposição a intempéries (sol, chuva, vento, poeira), ao risco de picadas de animais peçonhentos, entre outros, como também em relação à exposição aos agrotóxicos que favorecem o aumento do índice de morbidade e doenças ocupacionais. "Eu mexo com veneno porque sou obrigado, às vezes desanima trabalhar na lavoura por causa do veneno" (médio agricultor, 40 anos).

O sofrimento mental desses trabalhadores também não pode ser ignorado, sobretudo quando entra em ação a ansiedade gerada pela "disciplina da fome", a qual Dejours associou à necessidade de sobrevivência.

Esse tipo de ansiedade manifesta-se de forma explícita nos entrevistados. O equilíbrio mental desses trabalhadores é constantemente abalado devido às ameaças provenientes do trabalho. Eles enfrentam, no cotidiano, a luta pela sobrevivência diretamente associada às condições climáticas. Eis, a seguir, alguns discursos registrados durante a entrevista coletiva:

A gente fica doido, não dorme pensando no plantio, na colheita, no financiamento.

Quando a gente fica preocupado com a colheita a gente não dorme. Fico ansioso quando não chove.

Quando questionado acerca das dificuldades que enfrenta ao atuar como produtor rural, um dos entrevistados comentou:

Hoje tudo é difícil, tudo é com colheitadeira, antigamente tudo era manual, o difícil é na parte financeira, o preço do veneno é muito alto. Tem o stress, tá precisando chover e não chove, às vezes tá colhendo e chove, fico nervoso e entrego na mão de Deus. Tem o problema do seguro, do preço, preocupação com o banco, fica de mãos atadas. (pequeno agricultor, 56 anos)

Tem gente que não dorme na hora de colher e plantar. (pequeno agricultor, 63 anos)

Nessa breve apresentação do tema, é possível percebermos que, nessa relação de trabalho, tanto a saúde física quanto a psíquica sofrem o impacto das más condições de trabalho. Não significa que não existam outros tipos de sofrimento. Limitamo-nos apenas a analisar esses dois temas que sobressaíram nos discursos dos entrevistados.

Foi intoxicação? Casos e causos: diferentes maneiras de lidar com a situação

Durante os relatos, os entrevistados contaram como sentiram os sintomas da intoxicação da qual foram vítimas. Falam de amigos, vizinhos e parentes intoxicados, não restando dúvidas quanto à importância em se ouvir os que conhecem e vivenciam a realidade.

Os principais sintomas apontados pelos entrevistados foram dores de cabeça, irritação nos olhos, tonturas, náuseas, excesso de saliva, desatenção. Eis um relato sobre tais intercorrências:

\section{N., 54 anos, usou veneno até 1974}

$\mathrm{Na}$ época passava veneno com máquina costal. O veneno ficava grudado na pele, então eu chegava em casa e minha esposa passava gasolina pra tirar o óleo da pele. A turma mandava tomar leite, hoje já sabe que tomar leite é pior... Atualmente tenho muito veneno no corpo, todo mês tenho que tomar remédio. Tenho fraqueza, o número de plaquetas que deveria ser 150 não atinge 80 . Tomo vitamina B12 para fortalecer o organismo, faz sete anos que tomo esse medicamento, sinto muita dor nos ossos, à noite não agüento de dor nos ossos... Intoxicado a gente é, se alguém passar veneno, sinto como se tivesse formiga mordendo no corpo.

O aumento à exposição pode estar associado também à pressa em terminar o serviço o quanto antes, na seguinte situação:

Estava passando... na época não tinha os recursos que tenho agora. Tava passando veneno com trator pequeno e a soja estava alta, levantei muito a barra do trator, começou um vento, queria terminar o serviço, o veneno foi cobrindo o corpo, comecei a sentir mal, tive febre, tontura, dor muscular e náusea. (pequeno agricultor, 54 anos) 
Segundo este entrevistado, após o surgimento dos sintomas, o mesmo foi para casa, tomou um banho, avisou a esposa e procurou atendimento médico. Foi então diagnosticada a intoxicação. Afirmou ainda que, ao sentir o cheiro do produto, sente formigamento no corpo.

Outro entrevistado relatou que há aproximadamente 20 anos estava aplicando veneno com máquina costal e começou a sentir dores de cabeça e tremores no corpo. Segundo ele, não fazia uso de EPI e estava ventando: "Hoje tem equipamento, naquela época não tinha”. Contou que o irmão o levou ao hospital e lá ficou tomando soro por três horas. Ainda segundo ele, antes de ir ao hospital, tomou salmoura para provocar vômito... "A turma falava que tinha que provocar vômito”. E só procurou atendimento médico porque não houve melhora.

Comentou também que na época foi orientado pelos agrônomos a tomar ampolas de uma medicação da qual não se lembra o nome: "Tomava de 3 a 4 ampolas por dia... com essas ampolas o cheiro do veneno saia pelos poros".

Outro entrevistado nos relatou a seguinte situação que havia ocorrido na semana anterior à entrevista:

Estava passando veneno, estava usando luva e máscara de proteção, não uso a roupa de proteção porque é muito quente, usei o canivete para abrir o frasco do veneno, coloquei o canivete na bainha e esqueci que estava com veneno, encostei a mão e cocei o olho, trabalhei o resto do dia com o olho ardendo. À noite depois do banho, fui na farmácia, o farmacêutico receitou um creme, usei apenas uma vez.. (pequeno agricultor, 34 anos)

Há mais ou menos três anos, estava passando... com bomba costal na lavoura de soja, estava no final da aplicação, senti frio e ânsia de vômito, foi embora pra casa tomei leite e a noite já estava boa. (pequena agricultora, 62 anos)

Neste último caso, a entrevistada já havia relatado que não faz uso de EPIs, protegendo apenas os pés com sacola plástica. Então perguntamos o que ocorreu de diferente naquele dia que poderia ter lhe causado esses sintomas: "Acho que fiquei muito próximo do produto na hora do preparo”.

"Há mais ou menos seis anos, tive um problema com aplicação de veneno, deu um grosseiro na pele, começou a empelotar (alergia na pele) o corpo inteiro."
Referindo-se ao ocorrido:

Ele (o veneno) levanta um pó, é um veneno que põe na semente de milho, abri o tanque que põe a semente e tive contato com o pó, normalmente pra plantar a gente não põe máscara, na hora de abastecer a plantadeira a gente põe, mas depois tira a máscara. (médio agricultor, 30 anos)

Em novembro de 2003, eu estava na roça comecei a me sentir mal, desci pra casa. Começou a formigar a boca, as pernas. Fui pra casa dirigindo o trator. Em casa tomei $600 \mathrm{ml}$ de refrigerante, daquele que vem na embalagem de vidro porque a da embalagem de plástico não é bom, vomitei. Foi o que me salvou, depois de meia hora soltou o intestino. Daí tomei um copo de soro desses comprado em farmácia. Liguei para uma colega que é médica e ela disse que o susto já tinha passado e que agora já estava tudo bem. Tudo normalizou e então não precisei procurar médico. (pequeno agricultor, 43 anos)

Dando continuidade, este mesmo entrevistado, ao responder sobre seu estado de saúde nos últimos cinco anos, comentou que tem apresentado alterações de comportamento, como irritação, o que é mais evidente quando aplica o veneno.

Há aproximadamente dois anos tomo medicamento para dormir. Isso depois que perdi duas lavouras, uma de soja e outra de milho, nos anos de 2000 e 2001, ambas sem seguro. Passei então a ter depressão e alterações de atenção.

Relatou também que sente o corpo cansado, além de fadiga. A pressão arterial, às vezes, está alterada, mas afirma não tomar medicamentos a fim de controlá-la. Faz tratamento e controle de triglicérides. Às vezes apresenta alergia na pele.

Outro entrevistado, ao falar sobre os sintomas, manifestou que sente excesso de saliva quando utiliza agrotóxicos: "Eu não tinha essas coisas quando não mexia com veneno, uso veneno desde de 1987, comecei plantar soja, daí não tem outro jeito”.

Há mais ou menos quatro anos meu irmão estava passando dessecante e eu estava incorporando, dois irmãos passando e eu e o outro incorporando. Ele ia com o trator na frente e eu ia atrás gradeando, ele ia na frente passando o veneno e eu ia atrás com a grade niveladora, aí eu senti que aquele pó estava fazendo mal pra mim. À noite eu comecei a ficar zonzo e vomitar. Durante o dia inteiro eu respirei o pó, o veneno misturado. 
Perguntamos então por quantas horas ele ficou respirando o veneno, ao que respondeu:

Pegamos cedo e só paramos pra almoçar. Ficamos uns três ou quatro dias passando, eu não me lembro bem. Deu o problema em mim, eu fiquei parado e os outros continuaram passando. À noite eu senti mal, fui na farmácia, falei pro farmacêutico: "eu tô assim, zonzo, com dor de cabeça, ânsia de vômito", daí o farmacêutico falou: "você está intoxicado", me deu um remédio, tomei o remédio e no outro dia já estava bom. Nunca mais peguei esse veneno na mão, sem máscara, sem luva. (pequeno agricultor, 42 anos)

Há aproximadamente um ano procurei um médico, Irislogista, para ver se o mesmo detectava alguma intoxicação pela íris. O médico detectou uns raios no olho e disse que era intoxicação, prescreveu um remédio chamado Vida e Vigor e para prevenir intoxicação, e orientou sobre a importância do uso de equipamentos. (pequeno agricultor, 38 anos)

Percebemos, ainda, pela análise das entrevistas, que há dificuldade em se realizar um diagnóstico preciso dessas intercorrências pela equipe da rede básica de saúde, o que denota a necessidade de treinamento técnico dessa equipe no que tange à sintomatologia apresentada sobretudo por agricultores e a relação com o manuseio de agrotóxicos. A falta de um diagnóstico preciso dificulta não só o tratamento, mas também a notificação da ocorrência, contribuindo para os índices de subnotificação na região.

De acordo com alguns relatos, percebemos que muitos profissionais, no entanto, desconsideram o nexo ocupacional em algumas situações, como no seguinte exemplo:

Há mais ou menos seis anos, eu estava colhendo, o vizinho tinha dessecado a lavoura, eu sabia que ele tinha dessecado, mas não sabia que tinha ido veneno na minha lavoura. Comecei a colher e senti o cheiro. Estava na colheitadeira, estava sem máscara, porque pra colher não precisa usar máscara, a máscara incomoda muito. Comecei a me sentir mal então fui para casa. Fiquei mal dois dias e então procurei um médico. O médico diagnosticou como gripe... Vem vindo uma gripe forte. Medicou com uma injeção e mandou para casa. Melhorou um pouco no meio do dia, à noite eu piorei. Procurei novamente o médico e fui internado. O médico suspeitou de gripe, fiz vários exames. O pessoal da enfermagem achava que eu tinha aquela doença, mas o médico disse que não ia pedir exame para isso porque me conhecia e sabia que eu era um homem direito que não tinha nada dessas coisas. De madrugada deu diarréia, foi aí que aliviou. No dia seguinte o médico deu alta e não deu o diagnóstico de intoxicação. E disse: é alguma coisa com que você se intoxicou. Depois de 3 ou 4 dias procurei os técnicos pra verificar se era intoxicação, então o técnico leu esse livro aí (apontou para um manual que estava sobre a mesa) esse aí, o pai dos burros, e então descobrimos que era a intoxicação pelo dessecante. (pequeno agricultor, 54 anos)

Segundo Carmo et al. (1997), os profissionais dos serviços de saúde em geral nem sempre dão conta da responsabilidade adicional, ética e de mediador no que tange ao reconhecimento do nexo causal dos quadros clínicos e à relação destes com os ambientes e processos de trabalho. $\mathrm{Na}$ opinião dos autores, isso corrobora para a subnotificação de registros de acidentes e/ou doenças ocupacionais, implicando na falta de medidas de prevenção e ações de vigilância.

De acordo com Rozemberg et al. (2004, p. 11), os motivos que explicam o fato de a história ocupacional não ser percebida como parte da história de vida dos sujeitos que buscam atendimentos em instituições de saúde:

é reflexo da lógica espoliativa, de pouca valorização do trabalhador, que permeia o desenvolvimento econômico da sociedade brasileira. Tal lógica perpassa os ensinamentos acadêmicos e insinua-se nas práticas profissionais.

Para Dias (1995, p. 81), a falta do estabelecimento do nexo no processo saúdedoença-trabalho decorre do:

Paradigma que orienta a prática médica tradicional e que se reflete na (de)formação dos profissionais de saúde para lidar com esta questão, além dos limites do conhecimento disponível face às rápidas transformações que ocorrem no mundo do trabalho.

Mediante os discursos dos entrevistados que relataram terem sofrido algum sintoma quando do uso de agrotóxicos, foram raras as situações em que o trabalhador procurou atendimento médico. Na maioria das vezes deixam de trabalhar, voltam para casa e não fazem nada. Há outras situações ainda em que se limitam ao atendimento farmacêutico. Diante desse fato, torna-se evidente que muitas das intercorrências relativas à saúde no meio rural sofrem de subnotificação e subdiagnóstico. 
Assim sendo, as fontes de dados dos sistemas de informação de intoxicação por agrotóxicos limitam-se apenas aos casos registrados, não apresentando, dessa forma, o quadro da realidade de todo o dano causado por esses produtos à saúde da população trabalhadora.

Rozemberg et al. (2004), ao analisarem as interpretações dos profissionais de saúde acerca das queixas de "nervos" no meio rural, descreveram que estes profissionais apontaram, nas entrevistas, o problema do alto índice de alcoolismo nessa população, principalmente masculina, uma vez que o álcool potencializa a intoxicação por agrotóxicos e vice-versa.

Entretanto, apesar de não haver, em nosso roteiro de entrevista, questões relacionadas ao consumo de álcool, em alguns relatos esse fator aparece associado aos sintomas de desorientação.

Quando questionados sobre sintomas de desorientação, alguns dos entrevistados relacionaram a desorientação ao uso de álcool: "De segunda-feira é bravo, fico meio ruim depois de beber no fim de semana" (pequeno agricultor, 52 anos).

Esse mesmo entrevistado, ao ser questionado sobre alterações de sono, afirmou: "Tem dia que eu não durmo, não tomo remédio, tomo umas pra ver se melhoro".

Segundo outro entrevistado:

Tomo cerveja quando chego em casa, se faz bem eu não sei, dizem que tem que tomar leite, mas é perigoso, eu tomo cerveja que não faz mal. (médio agricultor, 53 anos)

No entanto, entendemos que a relação entre consumo de álcool e uso de agrotóxicos merece ser precisamente investigada nessa região, pois, indiretamente, sabemos dos casos de alcoolismo que assinalam a necessidade de uma investigação mais acurada.

Para Dejours (1992), o papel do álcool está articulado com a ideologia defensiva. Analisando os discursos acima sob a ótica dejouriana, vemos que, no caso, a cerveja torna-se uma dose de energia que ajuda a enfrentar as condições de trabalho.

Os relatos ainda denunciaram diferentes formas de lidar com o problema, que se pronunciaram na expressão do coletivo "tirar o veneno do corpo", tais como tomar limão e tomar banho quente após a aplicação dos produtos.

Durante uma entrevista, um dos entrevistados relatou que consome carvão vegetal. Segundo o mesmo: "Tem um menino da cidade que passa vendendo produto natural, ele disse que o produto é bom pra tirar o veneno do corpo" (grande agricultor, 39 anos). O produto é denominado "Fonte da Vida”. O frasco que o entrevistado nos mostrou continha apenas alguns comprimidos: "Tomo só no dia que lembro".

Em meio às entrevistas, algumas vezes apareceram histórias de casos de intoxicação ocorridas com pessoas conhecidas, como parentes, amigos e vizinhos:

Um cara guardava veneno dentro do quarto, embaixo da cama porque tava tendo muito roubo, daí ele se sentiu mal, o médico desconfiou e orientou. (pequeno agricultor, 63 anos)

Um rapaz era acostumado passar veneno de bermuda e chinelo. Daí o fazendeiro exigiu que ele usasse EPI, ele não acostumou. Quando ele vestiu fez mal, levaro ele pra Marília, ele morreu. Acho que tem o momento das coisas, a gente trabalha meio livre, daí põe essas coisa, agente não se sente normal. (pequeno agricultor, 63 anos)

Meu cunhado abre veneno com a boca outro dia ele tava meio atrapalhado das idéia, ele dorme sem tomá banho depois de passá veneno. (médio agricultor, 38 anos)

Eu tenho um vizinho que intoxicou grave, teve que trocar até o sangue. (pequeno agricultor, 42 anos)

Em pesquisas realizadas com trabalhadores rurais, Peres et al. (2004) fazem referências aos relatos produzidos pelos entrevistados em terceira pessoa, como forma de transferir a possibilidade de intoxicação por agrotóxicos. Tais achados são analisados tomando-se como base o conceito de ideologia defensiva da abordagem dejouriana.

Assim sendo, na opinião dos autores, tal mecanismo defensivo corresponderia à forma de neutralização do medo diante do risco. Como apontou Dejours, este estratagema tem um valor simbólico que afirma a iniciativa e o domínio dos trabalhadores sobre o perigo. 


\section{Considerações Finais}

O contato com os produtores nos possibilitou conhecer alguns aspectos do cotidiano de trabalho do meio rural, dentre os quais se destacou o risco da exposição desses trabalhadores quando da utilização de agrotóxicos no desenvolvimento de suas atividades.

Revelou também que o fato de haver baixo índice de notificações de intoxicação por agrotóxicos na região estudada parece referir-se ao problema da subnotificação.

Os relatos dos entrevistados indicam que a subnotificação ocorre basicamente porque o trabalhador se utiliza de meios não-convencionais para eliminar os sintomas e não procura atendimento médico ou então, quando há procura de atendimento, o caso não é devidamente registrado pela equipe de saúde.

Neste sentido, destacamos a importância do efetivo funcionamento dos sistemas de informação de vigilância em saúde nos municípios desta região para gerar informações precisas sobre a realidade, a fim de que, a partir dessa fonte, ações de prevenção possam ser implementadas.

\section{Referências Bibliográficas}

DEJOURS, C. A loucura do trabalho. São Paulo: Cortez, 1992.

DIAS, E. C. O. Manejo dos agravos à saúde relacionados com o trabalho In: MENDES, R. Patologia do Trabalho. São Paulo: Atheneu, 1995. p. 59-85.

FARIA, N. M. X. et al. Trabalho rural e intoxicações por agrotóxicos. Cad. Saúde Pública [on line], v. 20, n. 5, 2004. Disponível em: http://www.scielo.br/scielo. php?script $=$ sci_arttext\&pid $=$ S0102-311X 2004000500024\&lng $=$ pt\&nrm $=i s o \& t \operatorname{lng}=$ pt.

MINAYO, M. C. S. O desafio do conhecimento: pesquisa qualitativa em saúde. São Paulo/ Rio de Janeiro: Hucitec/Abrasco, 1999.

. Pesquisa social: teoria, método e criatividade. Petrópolis: Vozes, 2002.

MOREIRA, J. C. et al. Avaliação integrada do impacto do uso de agrotóxicos sobre a saúde humana em uma comunidade agrícola de Nova Friburgo, RJ. Ciênc. saúde coletiva [on line], v. 7, n. 2, 2002. Disponível em: http:// www.scielo.br/scielo.php?script $=$ sci
Salientamos também que estas ações poderão ser fortalecidas na medida em que vários segmentos, como sindicatos rurais, cooperativas agrícolas, comunidades rurais, vigilância sanitária e epidemiológica, entre outros, trabalharem conjuntamente no sentido de criar estratégias de promoção da saúde.

Finalizando, destacamos que este estudo tem característica preliminar, cujo resultado aponta para a necessidade do desenvolvimento de novas pesquisas na região, as quais, a nosso ver, deveriam priorizar estudos sobre o quadro de intoxicações agudas e morbidade crônica relacionadas ao uso dos agrotóxicos.

Esperamos que os resultados aqui apresentados possam ser somados a outros estudos relacionados aos danos produzidos pelos agrotóxicos à saúde dos trabalhadores do meio rural, contribuindo para a denúncia desses agravos à saúde visando à criação de uma consciência ética acerca do problema por parte de órgãos e instituições responsáveis.

arttext\&pid $=$ S1413-81232002000200010\&l $\mathrm{ng}=\mathrm{pt} \& \mathrm{nrm}=\mathrm{iso \& t} \operatorname{lng}=\mathrm{pt}$.

PARAGUAY, A. I. B. B. Da organização do trabalho e seus impactos sobre a saúde dos trabalhadores. In: MENDES. R. Patologia do Trabalho. São Paulo: Atheneu, 2003. p. 811823.

PERES, F. et al. Percepção das condições de trabalho em uma tradicional comunidade agrícola em Boa Esperança, Nova Friburgo, Rio de Janeiro. Cad. Saúde Pública [on line], v. 20, n. 4, 2004. Disponível em: http:// www.scielo.br/scielo.php?script $=$ sci arttext\&pid=S0102-311X2004000400021\& $\operatorname{lng}=\mathrm{pt} \& n r m=\mathrm{iso} \& \operatorname{lng}=\mathrm{pt}$.

ROZEMBERG, B., LEVIGARD, Y. E. A interpretação dos profissionais de saúde acerca das queixas de "nervos" no meio rural: uma aproximação ao problema das intoxicações por agrotóxicos. Cad. Saúde Pública [on line], v. 20, n. 6, 2004. Disponível em: http:// www.scielo.br/scielo.php?script $=$ sci 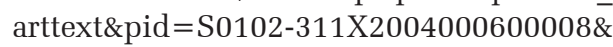 $\operatorname{lng}=\mathrm{pt} \& \mathrm{nrm}=\mathrm{iso} \& \mathrm{t} \operatorname{lng}=\mathrm{pt}$. 
SINAN. Sistema de Informações de Agravos de Notificação. Disponível em: http:// www. cve.saude.sp.gov.br/htm/cve. Acesso em: 18 dez 2004.

SINDAG. Sindicato Nacional da Indústria de Produtos para Defesa Agrícola. Dis- ponível em: http://www.sindag.org.br/new site/index.php. Acesso em: 18 dez 2004.

SINITOX. Sistema Nacional de Informação Tóxico-Farmacológica. Disponível em: http://www.fiocruz.br/sinitox. Acesso em: 19 dez 2004. 